\title{
Crítica a la Razón Binaria: poder empresarial y agenda global en el marco de políticas de protección del mercado local. El caso de Precios Cuidados en Argentina
}

\author{
Juan Pablo Quiroga \\ Georgetown University - Universidad de San Martín
}

\section{Resumen}

Suele ser una tentación del intelecto, ya sea por una búsqueda de economía argumental o fruto de un vestigio de la influencia del Estructuralismo, reducir la complejidad de lo social a opciones binarias. El proceso de globalización, sus consecuencias e implicancias, no escapó a esta tentación que, bajo el par liberalización/proteccionismo, invisibilizó la densidad implicada en los procesos de transnacionalización. Sus variantes y resistencias. En esta línea, el presente trabajo busca dar cuenta y reconstruir la complejidad de este entramado de relaciones, sobre la base del análisis del programa de Precios Cuidados y la aceptación (voluntaria) por parte del empresariado local, a partir de argumentar que el mismo constituyó una ventana de oportunidad para la gestión - en el marco de negociaciones más fluidas con el gobiernode intereses sectoriales ligados al flujo de comercio global. Intentaremos demostrar que sólo a condición de romper con ciertos vestigios de la "razón binaria", comienza a hacerse inteligible que, en los pliegues mismos de los diseños de ciertas políticas de protección de mercado, puede radicar la condición que alimenta el flujo de comercio global. Sólo entonces puede entenderse en toda su complejidad la relación entre las agencias estatales con su otredad: las estructuras del mercado.

Palabras clave: Controles de Precios, Poder Empresarial, Capacidad Estatal, Autonomía Estatal, Economía Política.

Critique of Binary Reason: entrepreneurial power and global agenda within the framework of local market protection policies. The case of Pricing Care in Argentina

\begin{abstract}
It tends to be a temptation of the intellect, either guided by a search for argument economy or the result of a vestige of Structuralism, to reduce the complexity of the social phenomena to binary options. The process of globalization, its consequences and implications, did not escape this temptation. In fact, under the pair of liberalization / protectionism, the density involved in the processes of transnationalization was made invisible. And so were its variants and resistances. In this sense, the present research seeks to account for and depict the complexity of this relationship, based on the analysis of Precios Cuidados policy in Argentina and its (voluntary) acceptance by local retailers. Our main argument is that it implied a window of opportunity -within a framework of more fluid negotiations with government officials- to manage interests related to global commerce flow. We will attempt to show that only on the condition of breaking with certain vestiges of "binary reasoning", it begins to become intelligible that in the very folds of certain market protection policy designs may lay the conditions that energizes global trade. Only then can the relationship between State and its otherness -the market structure- be understood in all its complexity.
\end{abstract}

Keywords: Price Control Policies, Business Power, State Autonomy, State Capacity, Political Economy.

*Dirección de correspondencia [Correspondence
address]: Juan Pablo Quiroga, Georgetown University
- Universidad de San Martín
E-mail: jq84@georgetown.edu




\section{Introducción}

Suele ser una tentación del intelecto, ya sea por una búsqueda de economía argumental o fruto de un vestigio de la influencia del Estructuralismo, reducir la complejidad de lo social a opciones binarias. El proceso de globalización, sus consecuencias e implicancias, no escapa a esta tentación reductiva y figuración monolítica. Aníbal Ford (1996), por ejemplo, denunciaba ya en 1994 las implicancias homogeneizadoras contenidas en la metáfora de "aldea global". Una idea que encubría la complejidad misma de los procesos de transnacionalización. Sus muchas variantes y resistencias.

En una palabra, a falta de herramientas epistemológicas que hicieran posible hacer inteligible la complejidad misma implicada en el "conventillo global" (Ford, 1996), liberalización o proteccionismo fueron entendidos como dos cursos de acción excluyentes.

En esta línea, el presente trabajo busca dar cuenta y reconstruir la complejidad de este entramado de relaciones, a partir del análisis del programa de Precios Cuidados ${ }^{1}$ en Argentina y la aceptación (voluntaria) por parte del empresariado del retail local. Argumentaremos que el mismo constituyó una ventana de oportunidad (Kingdon y Thurber, 1984) para la gestión -en el marco de negociaciones más fluidas con el gobierno- de intereses sectoriales fuertemente ligados al flujo de comercio global.

Intentaremos demostrar que sólo a condición de romper con ciertos vestigios de la "razón binaria", comienzan a hacerse inteligible que en los pliegues mismos de los diseños de ciertas políticas de protección de mercado, pueden radicar la condición misma que alimenta el flujo de comercio global.

En suma, buscaremos no sólo problematizar la frontera entre lo local y lo global, sino también la relación de las agencias estatales con su otredad: las estructuras del mercado. Después de todo, partimos de reconocer que en políticas públicas el enfoque sobre el Estado “(...) debe ser conjugad[o] con elementos que permitan abordar el otro extremo de la relación: los actores empresarios y sus formas de organización y acción" (Castellani y Llampart,2012:161). En otros términos, "el análisis sobre las estructuras estatales deben unirse con los

${ }^{1}$ El Programa de Precios Cuidados nace en Argentina en 2014 con un doble objetivo declarado: (a) asegurar condiciones de competitividad en la economía, y (b) que cada consumidor ejerza su derecho a elegir informado. Es decir, tras un análisis de la estructura de costos de los principales productos de la canasta básica, el diseño del programa buscaba establecer y dar visibilidad a productos con "precios de referencia" que contemplen "márgenes razonables" de rentabilidad. análisis de las estructuras de mercado" (Evans y Rueschemeyer, 1985: 51).

Estos objetivos nos pondrán, en lo sucesivo, en la triple necesidad de: analizar el estatuto efectivo del empresariado del retail al interior de las relaciones de poder en juego; así como dimensionar el alcance y significado de las cuestiones en debate a la luz de sus intereses, o -por lo menos- de cierta facción del mismo; y por último de entender las preferencias del mismo para con las cuestiones en juego. Un punto que nos obliga a hacer frente a un desafío metodológico de consideración, en vistas a que debemos poder ser capaces de distinguir las preferencias del comportamiento manifiesto (Hacker y Pierson, 2002:313). Un desafío que según algunos autores (Broockman, 2012) se habría cristalizado en una suerte de impasse y problemas de validación interna en muchas investigaciones, por las dificultades metodológicas implicadas en identificar intereses, cuando existen incentivos para tergiversarlos [misrepresent] en el debate público.

\section{La posición crítica del sistema de pre- cios y las invariantes en su debate}

El sistema de precios, así como su regulación/desregulación, constituye un objeto privilegiado para el análisis de la (presunta) frontera entre lo local y lo global por el estatuto particular que tiene al interior del sistema social. Después de todo, el precio de los alimentos nos pone frente a un debate que va más allá de las cuestiones de corte económico: nos sitúa frente a problemas políticos, como la constitución de alianzas de clase como fruto de la exportación de bienes-salarios y la necesidad de balancear el déficit fiscal (O'donnell, 1977); a dimensiones sociológicas, como las cuestiones relativas a los sistemas de producción y distribución de los alimentos; y dimensiones antropológicas, en vistas a que no se trata sólo de la posibilidad de acceder a bienes de consumo para reproducir la fuerza de trabajo, sino que involucra sistemas de valores, hábitos y costumbres que hacen a la identidad de los pueblos. Nos pone frente a gustos relativos a la nacionalidad, la identidad, la edad, la religión y el género, así como la división sexual del trabajo al interior de las unidades domésticas.

Incluso, en los últimos años las políticas de control de precio han sido una herramienta clave en la construcción de capacidades estatales (Quiroga, 2015) así - como intentaremos argumentar en el presente trabajo- una canal a través del cual de forma subrepticia la agenda internacional vinculada a circulación de productos globales logró permear las barreras de protección de los mercados locales. 
Dos cuestiones descuidadas a lo largo del debate académico.

Ahora bien, de la revisión bibliográfica y el devenir social de su debate en el tiempo, se hace manifiesto un conjunto de referencias semánticas y problemáticas propias y recurrentes, entre ellas: la preocupación por el rol y el tamaño de la burocracia (Taussig, 1919; Grayson y Neeb, 1974; Clinard,1969; Rockoff, 2004;Galbraith, 1941; 1946); la eficacia de corto plazo y la ineficacia de medianolargo de los controles (Rockoff, 2004; Grayson y Neeb, 1974; Bienen y Gersovitz, 1986, FIEL, 1990); la evasión y la constitución de mercados negros (Clinard,1969); la eventual violencia emergente tras el desmantelamiento de los controles o subsidios a los bienes de consumo (Bienen y Gersovitz, 1986; van Wijnberger,1992); su potencial impacto en la coalición de gobierno (Agéndor y Asilis, 1997); las preocupaciones por los niveles de entrega o incluso eventuales quiebres en las cadenas de abastecimiento (Grayson y Neeb, 1974; Clinard,1969); los incentivos/distorsiones en la distribución de recursos, como fruto de la alteración del sistema de precios (Galbraith, 1941; 1946; 1951;2001; Friedman y Friedman, 1990; Colander, 1984; Dunn y Pressman, 2005); la búsqueda de alternativas focalizadas con miras a optimizar el uso de recursos a partir de limitar el denominado free-riding (Adams, s/f; Alderman, 2002; Gutner, 2002); e incluso (k) su devenir histórico como respuesta al alza de precios (Schuettinger y Butler, 1979), por mencionar algunos.

Sin embargo, todas estas referencias bien pueden organizarse sobre la base de dos pares de tensiones. En primer lugar, un eje caracterizado por valoraciones de orden deontológico, fundamentalmente, en lo relativo a si el Estado debe, o no debe, intervenir en la formación de precios en particular y en la economía en general. Un continuo entre dos polos, uno en favor de la intervención estatal y otro que promueve el libre concurso de las fuerzas de mercado y el sistema de precios como instrumento para la asignación eficiente de recursos.

En segundo lugar, en cambio, tendríamos un eje de orden técnico, vinculado al acceso previsto por los acuerdos. De esta forma, un polo quedaría definido por la universalidad, en donde todos - por su sola condición de ciudadanos- accederían a los beneficios del programa precios, mientras que en el otro extremo se encontraría la focalización, sobre la premisa de optimizar los gastos de funcionamiento a partir de identificar un segmento de la población como beneficiario.

El aspecto técnico de este eje, pondría atención no sólo sobre la identificación, selección y provisión de servicios a la población beneficiada, sino tam- bién en los costos administrativos implicados, así como también en el eventual impacto negativo en términos de estigmatización por los criterios de elegibilidad comprendidos.

Se configuran, entonces, cuatro cuadrantes, marcados por una tensión analítica subyacente entre garantizar el acceso a bienes de consumo (Universal; Estado) y la eficiencia en la distribución de recursos e identificación de la población más necesitada (Focal; Mercado).

Una segunda invariante, estaría dada por la estabilidad (relativa) de las formas que asumieron los controles en el tiempo. De hecho, de la literatura se desprende una tipología de cinco hechos estilizados en materia de controles de precios directos. En primer lugar, los "precios vigilados" en donde la atención se centra en las cadenas de comercialización, las cuales deben avisar a la Secretaría de Comercio sobre eventuales cambios en los precios. En segundo término, el denominado "acuerdo de precio", por el cual empresas comercializadoras y proveedores pactan los valores de un grupo de productos. Una tercera opción, en cambio, es denominada, con frecuencia, "precios controlados" y consiste en la necesidad por parte de productores y comercializadores de obtener aprobación del Gobierno para realizar cambios de precios. En cuarto lugar, existirían los "precios máximos" por los cuales la autoridad competente fija "techos" para determinados productos; mientras que, por último, residiría el "congelamiento generalizado" por un tiempo determinado, en los cuales se restringe de forma absoluta los cambios en materia de precios.

A esta estabilidad relativa de la formas, se le suman ciertas políticas indirectas de control de precios. Entre ellas, las más recurrentes suelen ser (a) subsidios generales al consumo; (b) sistemas de auto-focalización [self-targeting] (Adams, s/f:4); (c) exenciones impositivas; (d) establecimiento de cuotas y mecanismos de racionalización del tipo firstcome-first-served y (e) identificación de dinámicas y canales de consumo diferenciados por segmentos sociales, con miras a su identificación y focalización (Alderman, 2002:4-11) ${ }^{2}$.

\footnotetext{
${ }^{2}$ De hecho, durante el bienio 2014-2016, han coexistido, bajo diversas manifestaciones visibles, diferentes articulaciones de estas modalidades no sólo en Argentina, sino también en Egipto, Venezuela y Estados Unidos. Cuatro países que bajo el mismo objetivo de garantizar el acceso a determinados bienes de consumo, proponían entonces cuatro modalidades y diseños de política pública diferentes: la subvención a productos preferencialmente consumidos por sectores sociales vulnerados, en el caso de Egipto; precios acordados (de forma voluntaria) con el empresariado para una cantidad limitada de productos, en lo que respecta a Argentina; precios congelados de forma compulsiva para el total de la economía, en lo que hace a Venezuela; y transferencias de recursos a sectores de bajos ingresos para el consumo en de-
} 
Figura 1: Posicionamiento relacional de la literatura de referencia en base a los ejes en cuestión

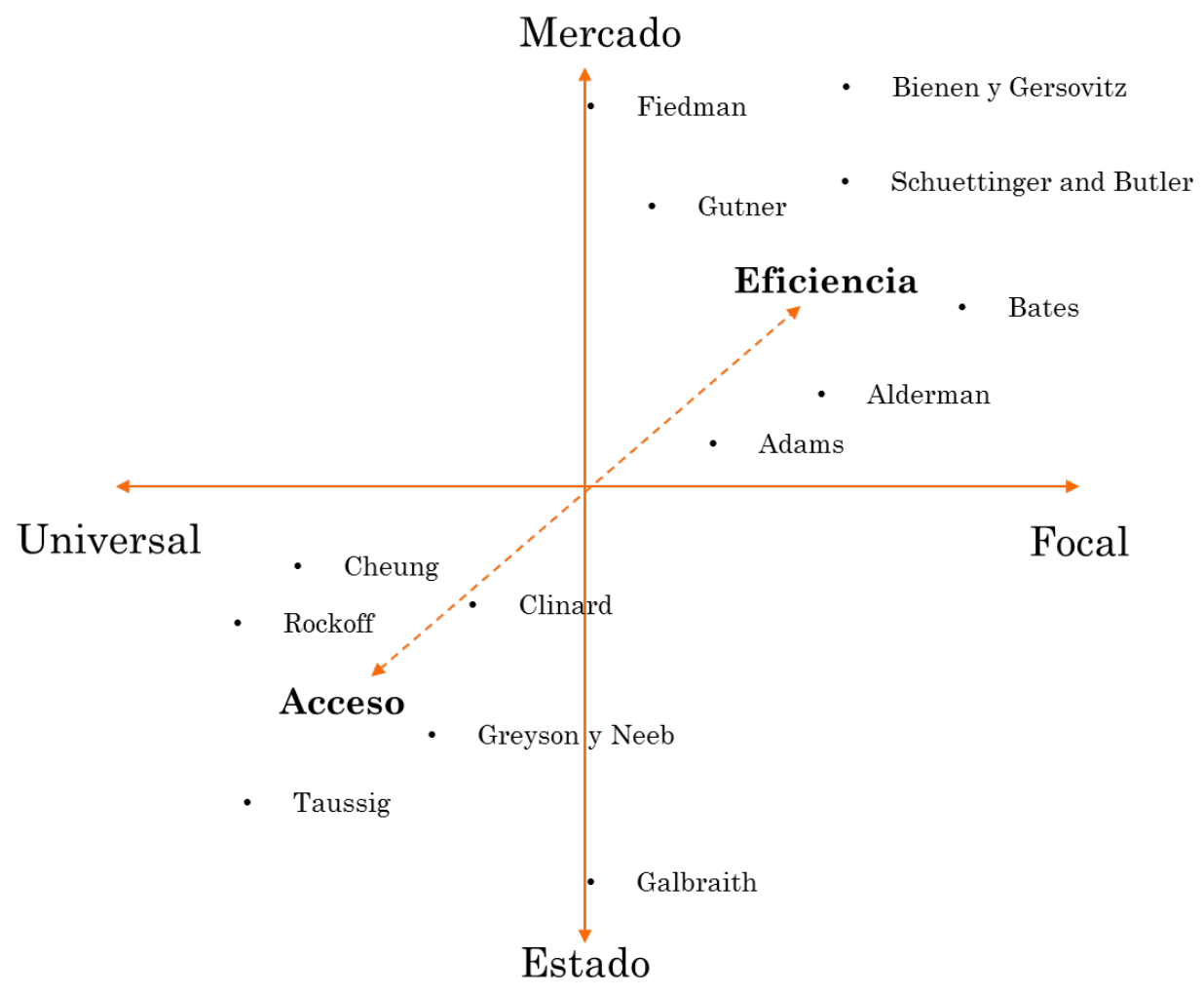

Fuente: Fuente: Elaboración propia

Por otro lado, existiría una tercera propiedad invariante en el análisis, la cual sólo se haría evidente por su omisión en el debate: la discusión sobre las capacidades (presuntas) del Estado, en vistas a que toda la discusión sobre las políticas de control de precios da por hecho, como constante, la existencia de capacidades para su realización.

Las diferencias, en cambio, sólo radicarán en el acento valorativo (+/-) en que se enmarque mencionada intervención, pero nunca son puestas en duda en su existencia. Es decir, o bien el Estado tiene capacidades para controlar los precios, o bien para distorsionar el sistema de mercado, pero bajo ningún punto no tiene capacidades: en el peor de los escenarios, resultan ineficientes, pero nunca noson.

Se trata, en suma, de un caso particular, de un fenómeno general que ha sido denominado "policy feedback" (Pierson, 1993) y que consiste en considerar a las políticas públicas no sólo como outputs, sino también inputs del proceso político. Incluso, algunos estudios se han realizado en esta línea, como el desarrollado por Ryan Saylor, quien plantea que el boom de exportación de commodities en Chile a finales del 1800 posibilitó la expansión de las

terminados canales de venta, como ocurre con el programa SNAP en Estados Unidos. capacidades del Estado, a partir de la provisión de bienes públicos y el desarrollo de instituciones que protegieran los intereses creados por parte de los grupos económicos dominantes (Saylor, 2012).

Asimismo, de esta consideración sobre las capacidades (presuntas) del Estado se desprende una segunda consecuencia de vital importancia para nuestro análisis: el rol secundario del empresariado en las formulaciones de las políticas en cuestión. Sobre todo, cuando la capacidades estatales se ven incrementadas como fruto de la aceptación del empresariado a brindar mayor información y someterse a mayores controles (Quiroga, 2015). Aún así, su accionar se nos presenta como "adaptativo" al poder del aparato estatal, sin que se encuentren referencias sobre su accionar durante el proceso de definición previo a la implementación de los controles. Es decir, el accionar del empresariado se figura de segundo orden -en respuesta y subordinado- al del Estado.

\section{Los controles en Argentina y el naci- miento de Precios Cuidados}

En cuanto al caso argentino, el país no fue la excepción al uso de los controles de precios durante 
el Siglo XX. De hecho, los mismos nacieron formalmente en 1939 como medida de excepción en el marco mismo de la Segunda Guerra Mundial, ante la amenaza de alteración de los flujos de comercio internacional.

En este contexto, el Congreso sancionó la Ley 12.591, la cual sería prorrogada de forma recurrente en 1952 (Ley 14.120), 1955 (Ley 14.440 y Ley 12.830), para - a partir de la Ley Nacional de Abastecimiento de 1964- pasar a ser fundada no ya en un régimen de excepción sino en una función más del Estado. Desde entonces, se sucederán varias leyes destinadas reglar estas facultades: en 1966 se sancionaría la Ley 17.017 y tras su vencimiento la Ley de Ordenamiento Económico 18.691/70, hasta que en 1974 se sancionaría la Ley 20.680 o Ley de Abastecimiento en vigencia hasta su modificación en 2014.

Asimismo, en el lapso comprendido entre 1967 y 1989, por ejemplo, los períodos de "libertad de precios" quedarían limitados a 30 meses, sobre un total de 274 (FIEL, 1990). Desde 1991 hasta enero de 2002, en cambio, se registraría un congelamiento en las presiones inflacionarias, como fruto de la puesta en marcha de la denominada Ley de Convertibilidad, limitándose los controles de precio fundamentalmente- a los servicios públicos. No obstante, a partir de 2005, y en lo relativo a bienes de primera necesidad, los controles volverían de forma progresiva, hasta un congelamiento, por 60 días, en febrero de 2013, circunscripto sólo a 500 productos a partir de mayo de ese mismo año.

Durante esos años, el tema de "seguridad alimentaria" ocuparía lugares preferenciales en las agendas globales de políticas públicas, como fruto del incremento sostenido desde el año 2000 en el precio internacional de los alimentos. Incluso, los organismos multilaterales, las agencias de cooperación y las organizaciones de la sociedad civil se vieron en la necesidad de revisar la definición misma del problema y sus causas, a la luz de los efectos contradictorios de mencionado alza, en donde el incremento en el costo de los alimentos dificultaba el acceso a los mismos, pero a la vez mejoraba los términos de intercambio de los pequeños y medianos productores (Swinnen y Squicciarini, 2012).

En este marco, a partir de 2004 comenzarían a registrarse alzas sostenidas en los principales indicadores en la materia, fundamentalmente en el índice mundial del precio de los alimentos y el índice de precios al consumidor. De hecho, en Argentina, la primera acción estatal estaría dirigida a intervenir el sistema de producción de los indicadores mismos, como respuesta a la búsqueda por relativizar el carácter socialmente problemático del alza de precios.

Asimismo, en 2003 accedería al ejercicio del gobierno una nueva coalición que buscaría incrementar las bases de su apoyo popular (tras ocupar a la Primera Magistratura con un escaso 22,24\% de votos positivos) a partir de incentivar el consumo, promover mayores niveles de empleabilidad, mejorar el alcance del sistema de protección social (y consecuentemente ampliar el gasto público), así como modificar el perfil productivo hacia una reindustrialización y alcanzar una mayor intervención del Estado en la economía, sobre todo en sectores estratégicos como servicios públicos, energía, aeronavegación, entre otros.

Es interesante notar, en este punto, que parecería prefigurarse una tensión entre el alza de precios y la necesidad de ampliar las bases de legitimidad del gobierno, a partir de incentivar el consumo y ampliar el sistema de protección social. Sobre todo, porque a nivel de las soluciones disponibles, sólo se verificaban dos alternativas con consenso entre ciertas coaliciones promotoras: el denominado "congelamiento de la economía" (fruto de políticas fiscales y de restricción monetaria), o bien los controles directos de precio que habían sido la norma durante más de 45 años en el país. Dos cursos de acción que atentaban contra el proceso de construcción de legitimidad de la nueva coalición, sobre todo de cara a la opinión pública y la base electoral en cuestión.

En cambio, las agencias de gobierno implicadas, fundamentalmente la Secretaría de Comercio Interior (SCI), optarían por un tercer curso de acción: el control de las manifestaciones visibles. En este marco, a la intervención al sistema de producción de índices oficial, a partir de la designación de una nueva dirección en el Instituto de Estadísticas y Censos, así como el diseño de un nuevo instrumento de medición de precios al consumidor ("La intervención de Moreno al INDEC...", 2012), se sumarían controles y acuerdos informales (de palabra) con las principales cadenas de distribución de bienes de consumo masivo y el Secretario de Comercio (de forma personal) para el mantenimiento de determinados precios ("Moreno presentó un acuerdo de precios...", 2007); campañas de ventas de productos alimenticios itinerantes por los barrios (como "Carne para Todos" "Pescado para Todos", por mencionar algunos) ("Cristina lanzó el...", 2011); denuncias a consultoras económicas, con multas que ascendieron hasta los $\$ 500.000$ por la publicación de estimaciones de precios minoristas ("Oficializan multa de Moreno...", 2011); congelamiento de precios de 500 productos ("los 500 básicos que...", 2013), hasta alcanzar un congelamiento total de los precios por tres meses en 2013; y la presentación de una tarjeta de crédito ("SuperCard") para brindar 
Figura 2: Índice Mensual de Precio de Alimentos

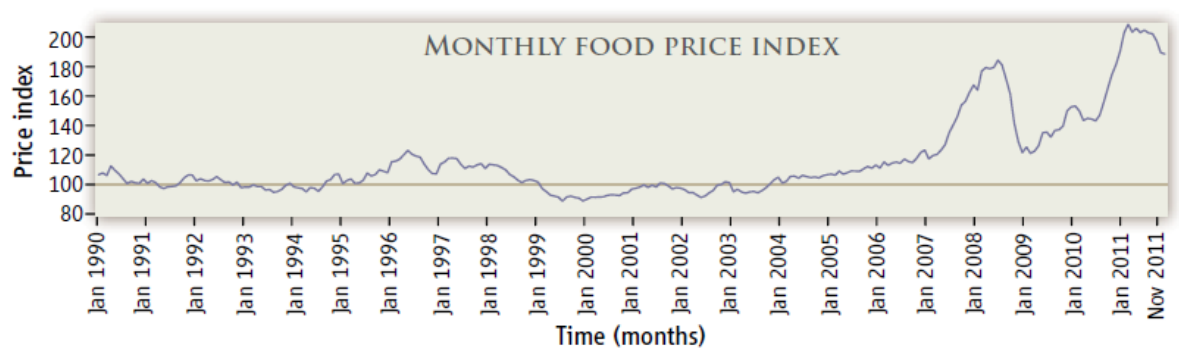

Food price index. Weighted average of meat, dairy, cereals, oil and fat, and sugar price indices. The average during 2002-04 is set to 100. Data from UN FAO, deflated using the World Bank Manufactures Unit Value Index.

\section{Fuente: Swinnen y Squicciarini, 2012}

mejores condiciones que aquellas ofertadas por los bancos y supermercados ("Con Moreno a la cabeza...", 2013).

No obstante, a principios de 2014, en cambio, se evidenciaría una serie de cambios que reconfigurarían este escenario. En primer lugar, Argentina afrontaría un escenario de devaluación, y consecuente pérdida del poder adquisitivo, del orden del $40 \%$, a la vez que los índices de inflación registrarían la mayor alza mensual del período al alcanzar un $4.5 \%$ en enero. Un tema que progresivamente devendría en un asunto de alta sensibilidad para la opinión pública (figura 3) hasta evidenciar en enero de mencionado año un crecimiento de las expectativas negativas sobre la situación económica personal y del país (figura 4).

Por otro lado, se verificarían cambios en carteras claves del Gobierno, fundamentalmente en el Ministerio de Economía (y la Secretaría de Comercio) y la Jefatura de Gabinete de Ministros; a la vez que -poco a poco-, y ante presión de la opinión pública y el crecimiento de las expectativas negativas a futuro, con su consecuente impacto en los niveles de aprobación de gobierno, comenzaba a hacerse evidente la necesidad de una nueva toma de posición por parte de las agencias estatales implicadas.

Es en este contexto, al calor de enero de 2014, que nacería el Programa de Precios Cuidados. Un acuerdo entre la Secretaría de Comercio, los supermercados, los distribuidores y sus principales proveedores para la administración de los precios de un set (inicial) de 194 productos.

El mismo tendría por objeto asegurar las condiciones de competitividad de la economía y que cada consumidor pueda ejercer su derecho a elegir informado. De esta forma, diseño mismo del programa buscaría establecer y dar visibilidad a una canasta de productos con "precios de referencia" que con- templen "márgenes razonables" de rentabilidad.

En su etapa inicial, el programa buscaría administrar el precio de 194 productos, producidos por 75 empresas proveedoras y distribuidos por 10 cadenas de supermercados de todo el país. Sin embargo, a lo largo del año 2014 el mismo fue incorporando nuevos ítems, como fruto de las revisiones trimestrales, hasta llegar al día de hoy -al momento de escritura del presente - a administrar una canasta total de 455 ítems, con aumentos en los períodos mencionados del orden del $3 \%$ en promedio.

El programa sería rápidamente aceptado por la opinión pública, registrando un alto nivel de conocimiento y valoración. De hecho, según una encuesta nacional de IPSOS-Mora y Araujo, el $96 \%$ de los consultados en el mes de noviembre de 2014 manifestó conocer el programa y su alcance. Incluso, el $75 \%$ del total de los mismos, a nivel nacional, declaró -en el mismo período- haber buscado al menos un producto del programa, siendo el $81 \%$ de ellos responsables principales de las compras del hogar.

Asimismo, determinadas categorías de productos dentro del programa, se perfilarían como la principal opción en el orden de preferencias de los clientes: en productos de almacén, por ejemplo, el $74 \%$ de los consultados declararía buscar productos de Precios Cuidados como primera opción, mientras que ese número llegaría al $69 \%$ en lácteos y $66 \%$ en productos de limpieza.

Por otro lado, la demanda durante el primer año se multiplicaría - en promedio- siete veces, a la vez que en el mismo período, según fuentes del sector, los productos que forman parte del programa habrían pasado de representar el 5\%, al $20 \%$ de la facturación de las grandes cadenas del retail local.

El andamiaje jurídico del programa supondría un 
Figura 3: Evolución de los principales problemas del país ¿Cuál es el problema más grave en el país? ¿` en segundo lugar? ¿Y en tercer lugar? Se muestran los valores de Total menciones

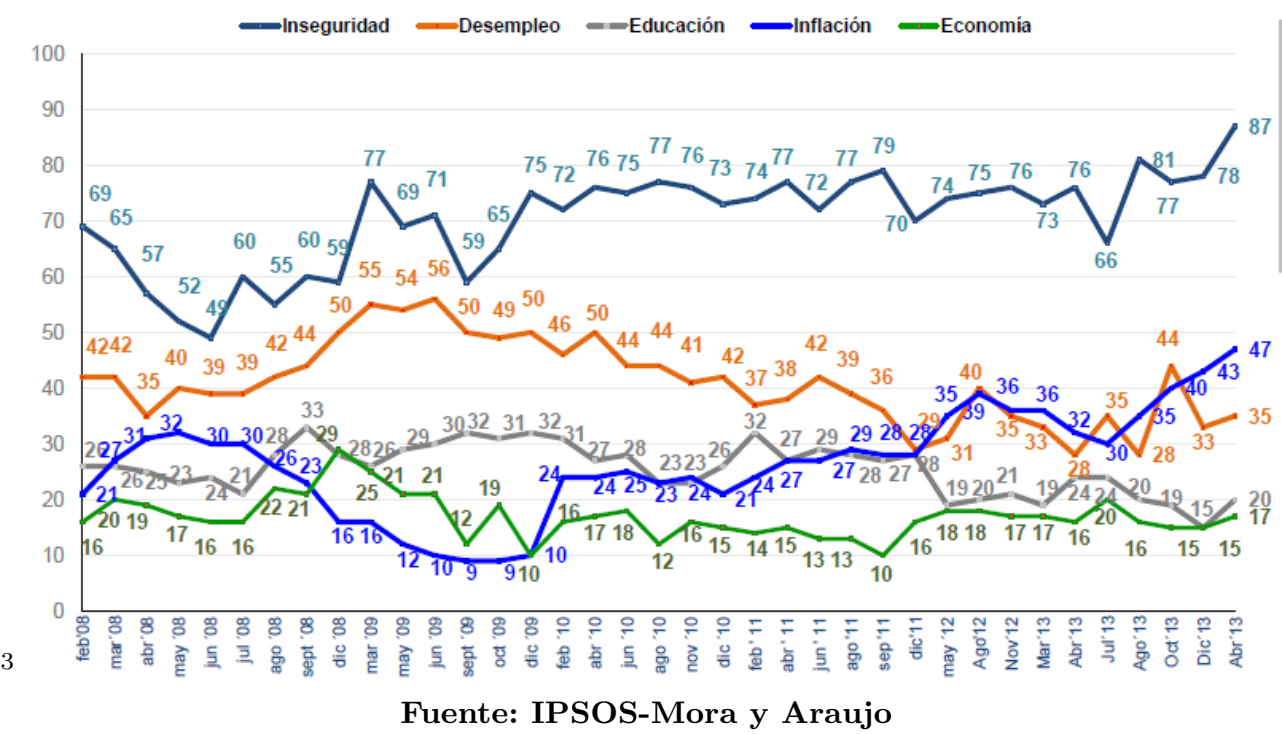

Figura 4: Expectativas a Futuro ¿Cómo cree ud. que estará .................... dentro de un año?

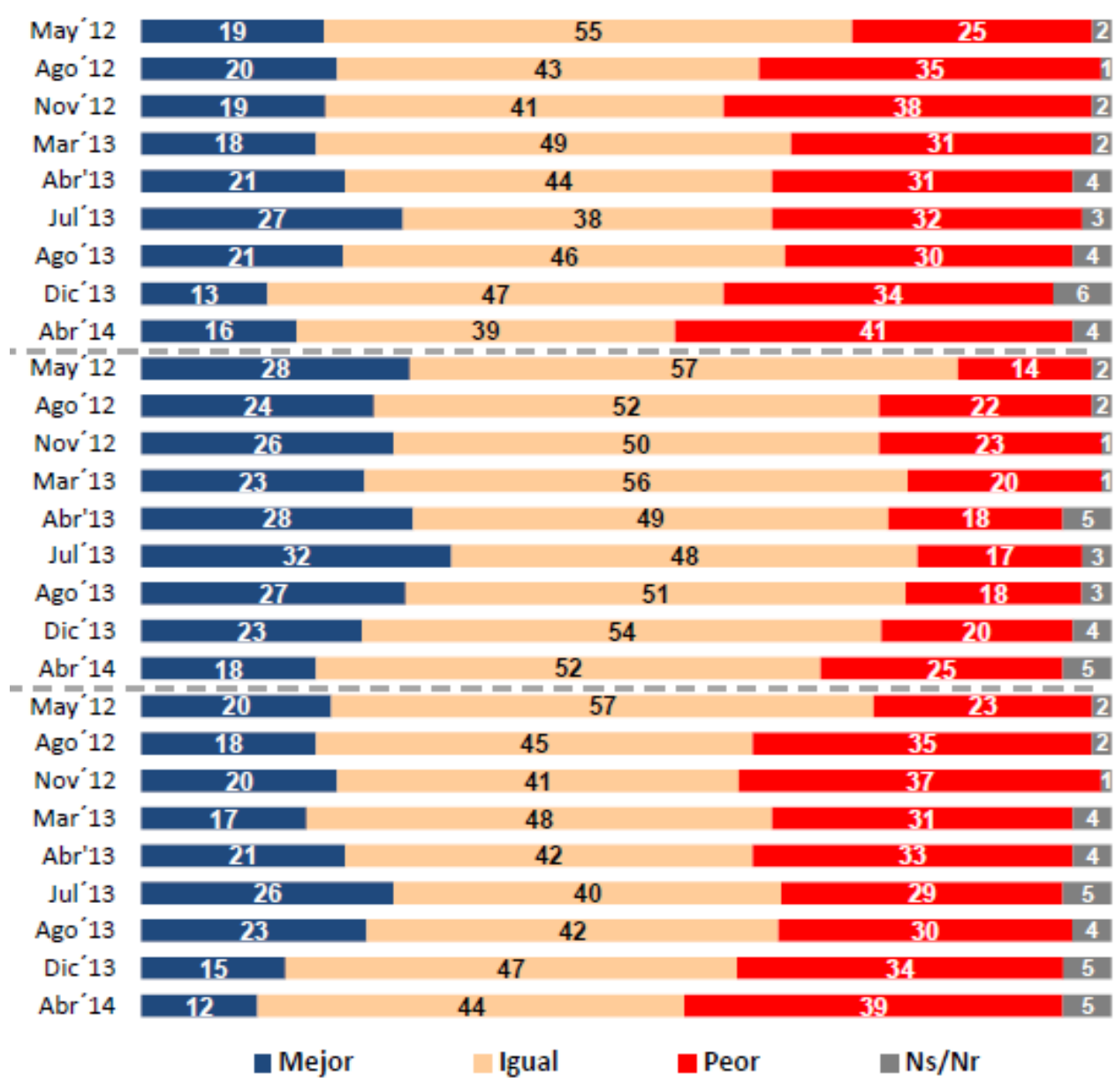

Fuente: IPSOS-Mora y Araujo 
elemento clave en sí mismo, porque a diferencia de las políticas de congelamiento de precios, en esta oportunidad el accionar del Estado se encontraba instrumentado en un acuerdo formal, y no sólo de palabra, con la SCI, el cual sería publicado en el Boletín Oficial (BO) con fecha 12 de enero de 2014, bajo la Resolución 02/2014.

La resolución da cuenta de dos series de acuerdos en paralelo. En primer lugar, aquel firmado entre la SCI y las cadenas de supermercados, donde las mismas aceptan de forma voluntaria comercializar y poner a la venta los productos definidos, al precio acordado; mientras el segundo, en cambio, sería firmado con cada proveedor de los productos previstos en la canasta, donde éstos últimos se comprometían a garantizar los niveles de entrega y el precio establecido.

Otra propiedad distintiva radicaría en su economía jurídica: se trataría de una serie de diez cláusulas breves, de suscripción voluntaria, sustentadas sobre un corpus jurídico de referencia compuesto por normas preexistentes: el artículo $42 \mathrm{de}$ la Constitución Nacional, el cual establece los derechos de los consumidores y usuario de servicios; la Ley 22.802 de Lealtad Comercial; la Ley 24.240 de Defensa del Consumidor; la Ley 25.156 de Defensa de la Competencia; y el Decreto 2136/2013 en donde se fijan los objetivos de SCI. Es decir, no se necesitaron nuevos elementos jurídicos, con los costos en términos de alianzas, negociación, debate con actores clave, entre otros, que esto hubiese implicado.

Ahora bien, en lo que a nosotros respecta, existen cuatro nudos jurídicos previstos por el acuerdo de especial importancia. En primer lugar, el mismo regiría únicamente para aquellos productos dados de alta a la fecha de firma del acuerdo. Es decir, las cadenas no tenían la obligación de sumar productos que aún previstos en la canasta del acuerdo no comercializaran al momento de la firma del convenio. Motivo por el cual, las cadenas no estaban obligadas conseguir proveedores, dar de alta productos, abastecerse y modular los mismos a sus tiendas, si ya no lo vendían. Posibilitando que pudiesen concentrar esfuerzos en disponer en cantidad de lo que ya tenían y no ampliar su base de surtido.

Asimismo, las partes se comprometían a revisiones trimestrales de precios, con la excepción de los productos de verdulería y carnes, los cuales serían sujetos a revisión mensual a pedido del supermercado, por la estacionalidad de los mismos.

En tercer término, un punto importante radicaría en la posibilidad de informar a la SCI de forma inmediata, a través del denominado "sistema de aler- ta temprana" cuando se verifiquen irregularidades en los niveles de entrega por parte de los proveedores.

Por último, las empresas comercializadoras asumían la responsabilidad por la señalización diferencial de los productos. Un sistema que mantendría características similares para todos, definidos por la Secretaría de Medios de la Nación y que sería objeto de multas en caso de no encontrarse conforme a lo estipulado.

De esta forma, comienza, poco a poco, a hacerse evidente dos hechos sustanciales. En primer lugar, la ejecución de Precios Cuidados se sostendría sobre una economía jurídico-administrativa sorprendente. Es decir, se estructuraría sobre la base de un convenio firmado con las principales cadenas comercializadoras y productores, y una serie de sucesivas adendas las cuales extenderían tanto el plazo de vigencia, como el alcance del programa. En segundo, las agencias de gobierno, fundamentalmente la SCI, contemplaría - a diferencia de las políticas informales llevadas a cabo hasta ese momento- las demandas del empresariado del retail local, sobre todo en lo relativo al abastecimiento, la necesidad de revisión de precios, un diferencial de aumento por región del país por los costos logísticos implicados en la comercialización, y la segmentación del surtido.

\section{El empresariado del retail local}

Ahora bien, un programa como el detallado en el apartado anterior, nos posiciona frente a una serie de preguntas centrales: ¿por qué el empresariado aceptaría voluntariamente una política de control de precios? Sobre todo, cuando tiene un impacto directo en su operación al reducir el margen de ganancia; limitar, consecuentemente, la definición de estrategias de posicionamiento diferencial, tanto comerciales como de marketing general, tanto como consecuencia de la estandarización de precios como por la intervención del piso de ventas con cartelería y señalética oficial; incrementar la interacción con las agencias de gobierno; y aumentar con los costos de transacción a partir de asignar recursos al funcionamiento del programa, tanto materiales como humanos.

Incluso aún más: si es cierto, como sostuvimos en otro lado (Quiroga, 2015), que esta nueva forma de articulación conjunta, prevista por el programa, entre el sector público y el privado, contribuye a ampliar las capacidades estatales a partir de mejorar, en la tipificación de Bertranou (2013), la legitimidad del sujeto estatal, los vínculos del Estado con actores no-estatales y las características de los 
arreglos institucionales y la estructura burocrática, ¿por qué el empresariado aceptaría contribuir a incrementar los poderes relativos de quien lo controla, sin garantías efectivas de límites a su ejercicio?

Un dilema aparente que nos podrá, como veremos, frente a la ruptura de las fronteras entre las políticas de protección y las agendas de liberalización, a la vez que en el centro de un problema metodológico, fruto del desfasaje entre el lugar de observador de los fenómenos sociales y el nivel de los actores sociales. Después de todo, sólo a los ojos del observador las acciones del empresariado (la renuncia a ciertos grados de agencia en la definición de su política comercial y de precios) es "irracional" o "contradictoria". En los pliegues de la dinámica social, en cambio, el empresariado se encuentra desarrollando apuestas en múltiples juegos; siendo en la concurrencia de los mismos, en su despliegue y encadenamiento, en donde se reencuentra la ( $\mathrm{su-}$ puesta) racionalidad pérdida (Tsebelis, 1990).

En una palabra, estamos ante una lógica de la elección aparentemente no óptima, que nos pone ante el desafío de reconstruir las arenas múltiples en donde se desarrolla el accionar del empresariado y en el marco de las cuales adquieren sentido. De lo contrario, seríamos víctima de un problema de "doble lectura" (Verón, 1995), en donde fenómenos de un nivel de análisis son interpretados al interior de las relaciones, del campo semántico y del universo referencial, de otro orden.

En este marco, reconstruir las arenas múltiples de despliegue del juego empresarial supone que, a continuación, dediquemos nuestros esfuerzos a comprender cabalmente al sector en cuestión, en nuestro caso a las empresas de comercialización de bienes de consumo masivo; así como el alcance y significado de las cuestiones bajo debate, para -finalmente- intentar reconstruir el contexto estratégico (Broockman, 2012) que le da marco y forma a las comunicaciones y declaraciones de los actores implicados (sus preferencias expresadas). Es en la variación en el contexto estratégico, donde encontraremos parte de la respuesta a nuestra pregunta sobre el orden de preferencias e intereses de los empresarios del sector.

\section{El mercado de venta minorista argen- tino}

Según estimaciones privadas, a junio de 2014 el sector de la comercialización de bienes de consumo masivo argentino reunía a más de 10.000 empresas, en dos canales: uno denominado comúnmente "tradicional" - compuesto por negocios de barrio, locales o de proximidad-, y otro "moderno", inte- grado por grandes grupos internacionales y nacionales, corporaciones minoristas y franquicias internacionales.

El denominado "canal moderno" del comercio minorista en Argentina nace en la década de 1950, con la inauguración el 17 de diciembre de 1951 del primer supermercado de Latinoamérica: "La Estrella Argentina".

El sector crecería de forma sostenida hasta desarrollarse con fuerza en la década de 1960, cuando en el mes de junio de 1960, se inaugura el primer local de Disco en Av. Centenarios 388, y en 1962 abre la primera cadena de capitales extranjeros: Minimaz. Sin embargo, en el marco de la crisis de la década de 1970 la Corporación IBEC decidiría vender los 16 puntos de venta que operaba en el país, la cuales serían en su mayoría compradas por El Hogar Obrero y operadas bajo bandera "Supercoop".

Hacia 1979, según datos de Nielsen, en la Argentina el número de supermercados había trepado a 392 , un $35 \%$ más que en 1975 . Por otra parte, ya para 1981 los supermercados concertaban el $22 \%$ de las ventas de los alimentos, con picos del $50 \%$ en ciudades como Mendoza, Mar del Plata y Córdoba. Asimismo, comenzaría el desembarco de grandes cadenas internacionales: ese mismo año el Grupo francés Carrefour llegaría al país con la apertura de dos tiendas y una inversión de 20 millones de dólares. En 1982, por otro lado, abriría las puertas el primer local de Jumbo y en 1988 llegaría la cadena mayorista holandesa Makro.

La década de 1980 sería el periodo de mayor expansión en el país de las ventas desde su inicio en 1951. Por otra parte, como efecto de la "internacionalización" del sector, se profundizaría el proceso de profesionalización de la gerencia local. En esta línea, en 1980 se realizaron las Primeras Jornadas Supermercadistas en Capital Federal con 400 asistentes, y en 1983 distintas cámaras provinciales iniciarían gestiones para la creación de la Federación Argentina de Supermercados y Autoservicios (FASA).

La década de 1990, por otro lado, quedaría marcada por el arribo de nuevos grupos internacionales y de una creciente concentración del sector. En este sentido, en 1995 se presentaría formalmente la cadena Walmart, a la vez que surgirían las tarjetas de crédito como medio de pago consolidado a partir de la firma de un convenio entre CADESA, el Banco de la Provincia de Buenos Aires y VISA.

Por otro lado, los primeros años del 2000 traerían consigo una mayor concentración de las operaciones: la cadena de Supermercados Norte sería comprada por parte de Carrefour en 2006, Disco por 
Cencosud y Auchan por Walmart. En 2010 Cencosud cerraría este proceso con la adquisición del 38,6 \% de la empresa Jumbo Retail Argentina y pasaría a controlar las cadenas Jumbo, Disco y Vea.

Asimismo, en 2004 nacería la Cámara de Autoservicios y Supermercados de Propiedad de Residentes Chinos (CASRECH) y el supermercadismo daría un giro decisivo de las grandes superficies a formatos de cercanía. De hecho, entre 2007 y 2008 nacerían los formatos compactos como Changomas (Walmart) y Carrefour Express, para luego avanzar en los desafíos de la multicanalidad con el desarrollo del comercio electrónico por parte de Coto y Walmart.

Al día de hoy, el canal tradicional representa el $70 \%$ del mercado, mientras el moderno se compone del $30 \%$ restante, del cual las principales seis cadenas concentran el $75 \%$ de la participación: $18 \%$ Carrefour, $17 \%$ Cencosud, $12 \%$ Coto, $11 \%$ Walmart, La Anónima $9 \%$ y Día el $8 \%$.

En términos de superficie, el sector puede clasificarse, a su vez, en cuatro formatos comerciales: los hipermercados (con un piso de venta que oscila entre 7.000 y $10.000 \mathrm{~m} 2$ ), los grandes supermercados (entre 1.500 y $2.500 \mathrm{~m} 2$ ), los supermercados de proximidad (de 350 a $1.000 \mathrm{~m} 2$ ) y los autoservicios (menores a $350 \mathrm{~m} 2$ ).

En el último tiempo, la composición y peso relativo de cada formato, tendió a migrar de las grandes superficies a los supermercados de proximidad, fundamentalmente por dos fenómenos complementarios: el cambio en los hábitos de consumo (un consumidor que realizaría, según las consultoras privadas, menos compras mensuales en cantidad y que se inclinaría hacia compras reducidas, de reposición, de 14 unidades promedio, en la búsqueda de precios bajos y ofertas ${ }^{4}$ ) y la reducción en la disponibilidad de terreno mayor a $5000 \mathrm{~m}^{2}$ para el desarrollo inmobiliario cercano a los grandes centros urbanos.

En suma, la proximidad -que solía ser un atributo del canal tradicional- poco a poco, empujado por el cambio en los hábitos de consumo y la disponibilidad de terrenos, comenzaría a ser un espacio de desarrollo para el canal moderno. De hecho, en términos comparativos, a mitad del 2014, el $92 \%$ de las nuevas aperturas de las grandes cadenas serían de formatos más pequeños y de proximidad (Kantor, 2014). Este punto tendrá una importancia central en lo relativo a la estructuración de las preferencias al interior del empresariado del retail.

\footnotetext{
${ }^{4}$ Según un estudio de Nielsen, 8 de cada 10 consultados manifestó, a marzo de 2015, haber cambiado sus hábitos de compra en vistas a ahorrar gastos: un $56 \%$ de los encuestados afirma haber cambiado a marcas más económicas de productos comestibles (Nielsen, 2015).
}

Volveremos sobre este punto.

Asimismo, el sector se organiza fundamentalmente- en tres Cámaras Empresariales. En primer lugar, se encuentra la Asociación de Supermercados Unidos (ASU), fundada el 19 de diciembre de 2003, y que nuclea a las grandes cadenas de supermercados, tanto nacionales como internacionales. Sus miembros, entre los que se destacan Carrefour, Cencosud, Coto, Walmart, La Anónima y Día \%, entre otros, representarían más del $70 \%$ de la facturación nacional del sector.

Incluso, la misma nacería como un desprendimiento la Cámara Argentina de Supermercados (CAS) y la Federación Argentina de Supermercados y Autoservicios (FASA), las cuales reúnen a su interior a los supermercados y autoservicios regionales.

El desprendimiento y la constitución de la nueva entidad tuvieron como correlato la emergencia de una nueva relación de fuerzas. A diferencia de la CAS, donde todas las empresas disponen -aún al día de hoy- de la misma cantidad de votos, al interior de ASU los socios están clasificados en tres categorías (y con diferentes votos) según su volumen de facturación.

Por último, se encuentra la Cámara de Autoservicios y Supermercados de Propiedad de Residentes Chinos (CASRECH), fundada en 2013 y que nucleaba a 19 Asociaciones Chinas de la República Argentina y 8.598 Supermercados en todo el país.

De hecho, el denominado "supermercadismo de origen asiático" nació en el país con la apertura de comercios de origen taiwanés desde 1983. A partir de 1989 venderían sus fondos de comercio a ciudadanos de origen chino que llegarían a radicarse en al país y quienes desarrollarían al sector de forma decisiva. En 1997 y 1998 tendría lugar una segunda oleada denominada "reagrupamiento familiar" y que constituiría un gran impulso, con un fuerte crecimiento exponencial, hasta 2011. Con los saqueos de mencionado año, cerrarían el $10 \%$ de los mismos y muchos no volverían a abrir.

No obstante, entre 2003 y 2014 los puntos de venta alcanzarían los 10.788 locales. Sin embargo, en palabras de referentes del sector, a partir de entonces, "el crecimiento cesó y esa cifra se redujo en los últimos 24 meses a 10.316 tiendas, un $65 \%$ de las cuales está en Ciudad de Buenos Aires y Gran Buenos Aires, y un $20 \%$ dividido entre Mar del Plata, Rosario, Posadas y algunas capitales provinciales".

En cuanto a sus características, es importante destacar que las empresas agrupadas sobre todo al interior de ASU responden tanto a los patrones 
de gobernanza corporativa que Schneider identifica de forma estilizada para la región (Schneider, 2008), como a las características empíricas del tipo definido por Economías Jerárquicas de Mercado o "HME", por sus siglas en inglés (Schneider, 2009).

En este sentido, puede decirse que estamos ante empresas multinacionales (Carrefour, Cencosud, Walmart, Libertad y Día \%) y empresas de capital nacional (Coto y La Anónima), donde estás últimas se caracterizan por la existencia de una propiedad concentrada y gerenciamiento familiar, así como diversificadas, a partir de la articulación con subsidiarias controladas jerárquicamente, con un porfolio de empresas que contempla frigoríficos, marcas propias en bienes de consumo, entre otras.

Incluso, en lo referente al mercado de trabajo, si bien podría discutirse -en lo relativo al promedio verificado en Argentina- la afirmación de Schneider sobre la existencia de relaciones laborales atomizadas y baja calificación de la mano de obra, lo cierto es que el supermercadismo como sector se caracteriza por ser un fuerte empleador de mano de obra de baja calificación. Incluso, suele ser el primer trabajo de muchos jóvenes con trayectorias escolares irregulares. Según números oficiales de las empresas en cuestión, las cuatro principales compañías (Carrefour, Coto, Walmart y Cencosud), emplean cerca de 55.000 trabajadores y se posicionan, entre los 10 principales empleadores privados del país (Lendoiro, 2012).

\section{El alcance de las cuestiones en debate y las preferencias manifiestas}

Las Cámaras sectoriales desempeñaron para el caso argentino un rol clave, no sólo por la reducción de costos de transacción en el marco de una economía de funcionamiento que posibilitaba negociar con un sólo interlocutor, sino también porque facilitaron la acción colectiva.

Puede decirse, en línea con los desarrollos de Schneider (2004) que el Estado resultaría un factor clave con miras a la organización de la acción colectiva del empresariado ${ }^{5}$, a partir de brindar la posibilidad de acceso a los círculos de policy making con regularidad formal (cada tres meses, necesariamente, el programa contemplaba revisiones y redefiniciones de productos, márgenes y precios, así como contactos semanales regulares para el reporte de las denominadas "Alertas Tempranas"), a la vez que serviría como un marco para evitar la exposición

\footnotetext{
${ }^{5}$ Sin embargo, este señalamiento no nos lleva a coincidir con el autor en su evaluación que en Latinoamérica las organizaciones sindicales son débiles y el empresariado es más dependiente y reactivo al Estado.
}

pública de los miembros de la Cámaras, a partir de canalizar -sobre todo durante los primeros seis meses- la exposición mediática a través de sus dirección ejecutiva.

En este sentido, el posicionamiento público del empresariado nucleado en ASU sobre el programa sería simétrico pero inverso no sólo a la intensidad comunicacional por parte de la SCI, sino también a la atención e interés social sobre el programa.

A lo largo de 2014, la SCI emitió -en promedio12 partes de prensa mensuales con especificaciones del programa, alcance, nuevos productos, precios, multas y novedades en general. Un ciclo que tuvo su pico en el mes de agosto, en el marco de la discusión por la nueva Ley de Defensa del Consumidor y la presentación de nuevos canales de compras oficiales (Red COMPRAR).

En términos del interés de los consumidores por el programa, los datos de Google Trends nos ofrecen un indicador posible a este respecto: entre enero y julio de 2014 se concentró el mayor interés de búsqueda en mencionado motor, para luego estabilizarse a partir de septiembre. Siendo la rúbrica "listado de productos" la búsqueda más realizada. De hecho, los picos trimestrales, coinciden con las renegociaciones y la publicación de los nuevos listados.

Sin embargo, el empresariado se mantendrá en silencio desde el inicio del programa, limitándose a una serie de apariciones por parte de representantes de ASU, al inicio del mismo, en enero de 2014. Una estrategia que cambiará, a partir del mes de octubre, incrementado las apariciones públicas de los presidentes de las cadenas miembro con declaraciones positivas para con el mismo.

En este sentido, en noviembre de 2014, en un foro empresarial, el presidente de Carrefour sostuvo que: "(...) el programa es bien valorado por los consumidores. En un contexto general de estancamiento, la venta de productos de Precios Cuidados crece $30 \%$; algunos con limitación de abastecimiento se multiplican por tres. Pero deja un sabor amargo, porque en la primera etapa el mérito para el consumidor era del Gobierno y cuando no se podía cumplir, la culpa era de los proveedores o distribuidores. Se necesita mucho compromiso de la cadena" (Rebon, 2014).

El presidente de Carrefour, de hecho, reconocería en otra entrevista que: "el año fue muy desparejo, pero para nosotros está terminando bien. El peor momento fue el segundo trimestre, cuando se resintió mucho el consumo, pero el canal de supermercados se defendió bien gracias a los Precios Cuidados y las promociones muy agresivas" ("Precios Cuida- 
Figura 5: Cantidad de Comunicados de Prensa por mes emitidos por la Secretaría de Comercio sobre Precios Cuidados

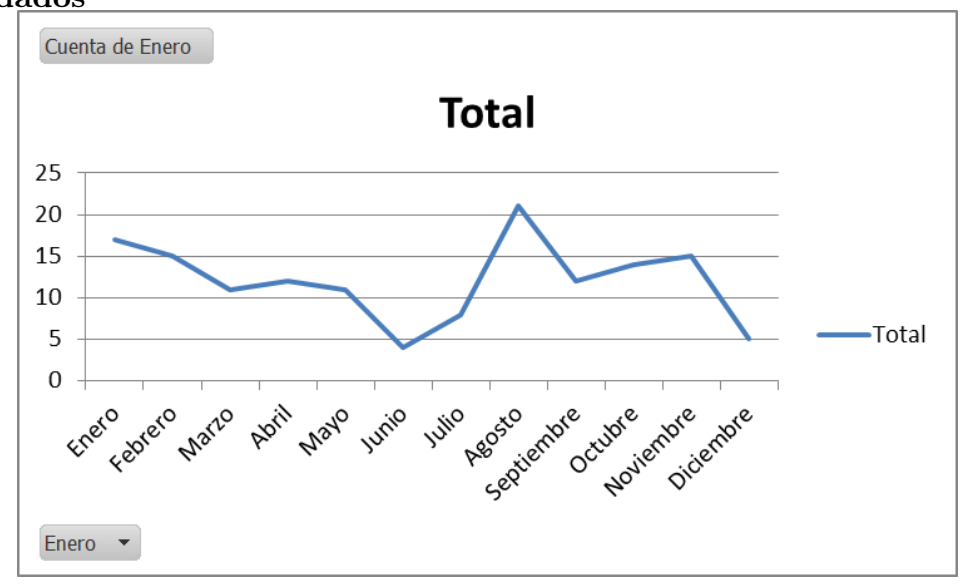

Fuente: Elaboración Propia

Figura 6: Interés por "Precios Cuidados" en el motor de búsqueda Google

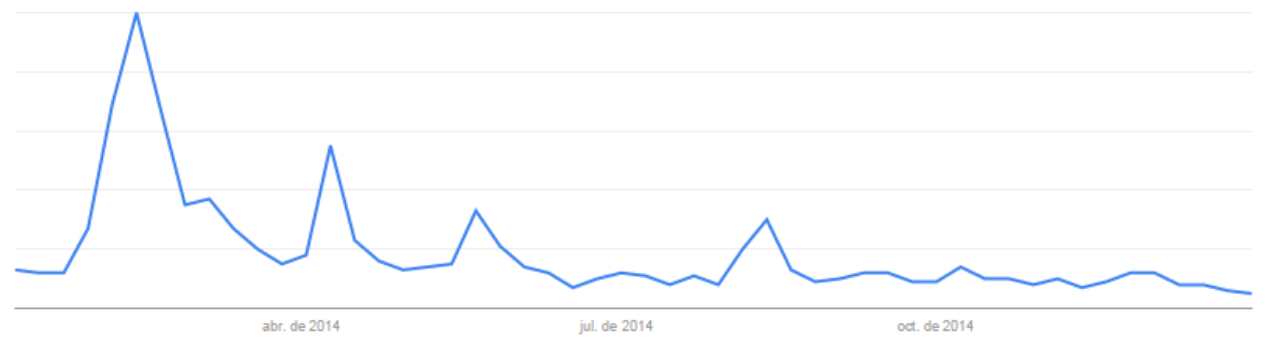

Fuente: Google Trends

dos Beneficia a las Cadenas", 2014).

Por su parte, Federico Braun, presidente de La Anónima, declararía en la agencia oficial TELAM que "nos fue bien porque tuvimos buena presencia en góndola de los más de 300 productos que forman parte del programa a lo que se sumó 'el énfasis que puso la campaña publicitaria masiva' que acompañó al plan. 'Nos está yendo muy bien por calidad, surtido y servicio y nos diferenciamos del sector informal que no cuenta con el programa" ("Afirman que los productos...", 2014).

Esta última declaración es sintomática, en vistas a que cristaliza en la superficie de la discursividad un elemento central. Un punto de quiebre al interior del sector: la preocupación por la participación de ventas del canal tradicional, y la ventaja competitiva que ofrecía el programa a las grandes cadenas.

De hecho, el optimismo declarado sobre el programa (aun con reservas sobre el abastecimiento), sobre todo con mayor intensidad con posterioridad a octubre del 2014, contrastaría a su vez con lo manifestado, por ejemplo, por los representantes de los supermercados chinos. En este sentido, el 16 de enero de 2014 el plan se extendió a las empresas nucleadas en CASRECH con un listado total de 50 productos, casi un cuarto del total disponible en las cadenas miembro de ASU (las cuales contaban, a su vez, con instancias de financiación, como el pago con tarjeta de crédito).

Sin embargo, las quejas del empresariado del sector no se harían esperar, hasta llegar a afirmar en un comunicado oficial de la Cámara, el 09 de julio de 2015, que: "los Súper chinos evalúan abandonar los Precios Cuidados. Lo afirmó Miguel Angel Calvete, Director Ejecutivo de la Federación de Supermercados y Asociaciones Chinas (FESACH) y Secretario Gral. de la Cámara de Autoservicios y Supermercados Propiedad Residentes Chinos de la República Argentina (CASRECH), luego que el Ministro de Economía, Axel Kicillof, anunciara anoche una nueva etapa del programa acordado entre el Gobierno Nacional y los supermercadistas. Reclaman que el plan estatal 'sigue priorizando a las grandes cadenas' y denuncian 'faltantes de productos contemplados en el acuerdo" ("Los Supermercados Chinos...", 2015).

Esta breve reconstrucción, pone de manifiesto un cambio en las declaraciones expresadas por parte del empresariado, tanto a favor del programa (ASU), como en contra (CASRECH). Un cambio (desde el silencio inicial, hasta la multiplicación 
de declaraciones finales), que evidencia subyacentemente, una modificación en el contexto estratégico que estructura las mismas.

\section{El orden subyacente: el con- texto estratégico y el juego de múltiples partidos}

Reconstruir las preferencias, más allá de los comportamientos manifiestos, implica, como dijimos, considerar y reconstruir el contexto estratégico que les da marco. En este sentido, se hace necesario dar cuenta de un horizonte temporal más amplio, que pone de manifiesto - por lo menos- la existencia de seis factores que nos permiten aproximarnos a los intereses del empresariado como actor social, y que contribuyen al esclarecimiento de la posición estructural del mismo al interior del debate en cuestión, a la vez que explican el porqué del cambio de posición que mencionábamos en el apartado anterior.

En primer lugar, a nivel de la opinión pública comenzaría a registrase un crecimiento en la preocupación por el fenómeno de la inflación, sobre todo desde mediados de 2009 en adelante, y de las expectativas negativas sobre la situación económica personal y del país (figura 3).

En segundo término, la trascendencia que tomaría el tema a nivel de la opinión pública, habría tornado imposible, por un lado, la no-toma de posición por parte del Estado y sus agencias, sobre todo por los costos electorales, al verificarse cierta correlación entre percepción de desempeño económico y evaluación de gestión de gobierno (figura 9).

Incluso, siguiendo los desarrollos de Culpepper (2010), estos dos primeros factores habrían codeterminado un tercero: la limitación del margen de acción del empresariado y el ejercicio del poder instrumental, siendo forzados - por el estatuto público emergente de la discusión y su reciente notoriedada encauzar el debate en torno a instituciones formales, limitando los beneficios que pudieron haber encontrado por parte del poder político en canales informales de negociación cuando -en los mismos términos de Culpepper- los votantes "no están prestando atención".

En una palabra, el estado público del tema, limitó las herramientas en materia de poder instrumental (Dahl, 1982; Lindblom, 1979), en términos de lobby, gestiones informales y consultas oficiosas, entre el sector y las agencias implicadas; a la par que creció la expectativa de una acción de gobierno y la legitimidad del sujeto estatal de cara a la intervención del mercado.

Una vez iniciado el funcionamiento del programa, estos factores condicionantes del poder empresarial, se agravarían, en vistas a los altos índices de aprobación social de Precios Cuidados: en términos de su aceptación pública, el programa registró un alto nivel de conocimiento a la vez que modificaría tendencias y patrones de consumo, en los términos analizados en el punto anterior. A su vez, el dato más significativo radicaría en que durante el año y medio que el programa llevaba en funcionamiento, Precios Cuidados pasaría de representar el $5 \%$ al $20 \%$ de la facturación de los supermercados.

En este punto, el lugar de la opinión pública y la presión que ejerce sobre el sistema político y sus instituciones parece ser sintomático. En un país con niveles de institucionalidad críticos y con escasa participación de las élites (políticas, empresariales, sindicales u de otro orden), como sectores dirigentes, sobre los procesos de formación de opinión, no es de extrañar, como sostiene Mora y Araujo, que "para entender a la Argentina [sea] preciso comprender a la opinión pública antes que a sus dirigentes (Mora y Araujo, 2011:17).

Por otro lado, un cuarto factor a considerar radica en el horizonte de mediano plazo en materia del calendario comercial del sector, el cual se encontraba marcado por las ventas de temporada (noviembre-enero) y la realización del Mundial de fútbol en junio de 2014. Un elemento central, sobre todo si se considera que la venta de temporada del último semestre del año representa -según fuentes del sector- cerca del $40 \%$ de la facturación anual, en sólo tres meses. A su vez, con ofertas de hasta 50 cuotas sin intereses en la edición de 2010, el Mundial había registrado resultados sorprendentes para el sector que esperaban repetir en $2014^{6}$.

Ambas cuestiones, por otro lado, dependían de la aprobación por parte de la Secretaría de Comercio, de las Declaraciones Juradas Anticipadas de Importación (DJAI). Es decir, la misma agencia de gobierno responsable por la defensa en el mercado interno de los criterios de lealtad comercial y precios, a partir de una reforma en su diseño institucional en 2011 era -a su vez- responsable de la revisión, autorización y control de los planes de importación. En palabras de los referentes consultados del sector: "el plan de importaciones de forma implícita, pero muchas veces de manera explícita, estaba condicionado (en lo relativo a electrodomésticos y textil, como en juguetes) al cumplimiento de Precios Cuidados y otros pedidos de la Secretaría".

\footnotetext{
${ }^{6}$ Sólo en el primer cuatrimestre del año 2010, la venta de televisores LCD en la Argentina había crecido un $320 \%$ respecto de igual período de 2009 .
} 
Figura 7: Correlación entre evaluación de desempeño de la economía y gestión de gobierno

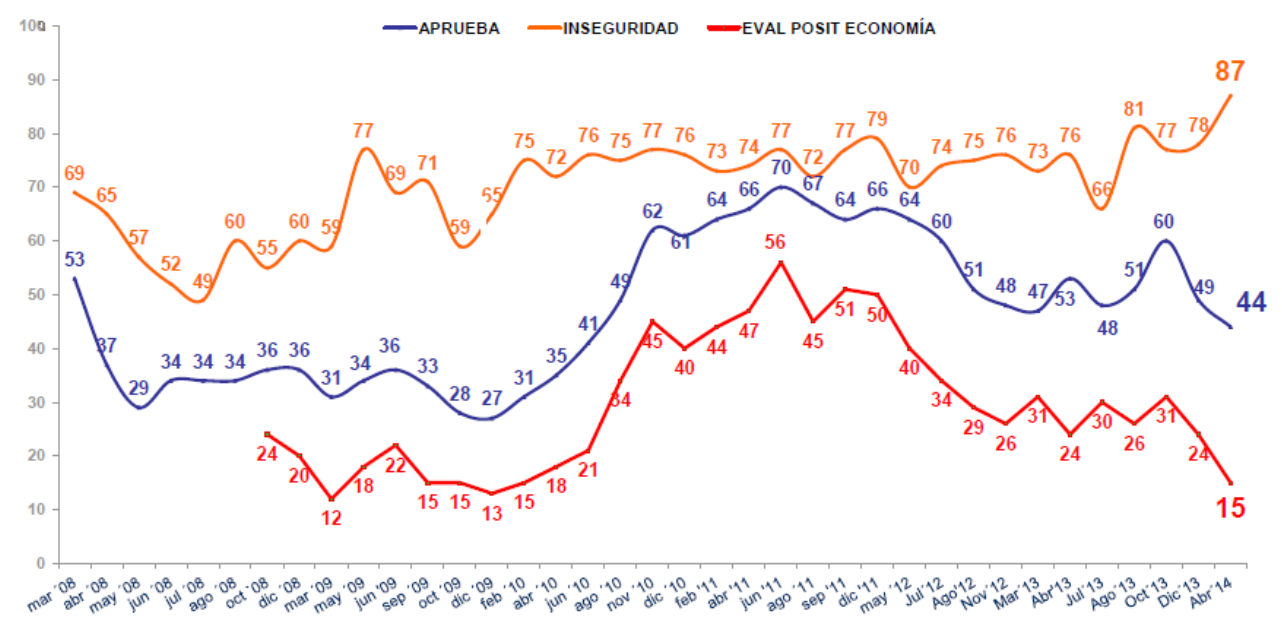

Fuente: IPSOS-Mora y Araujo

De hecho, en lo relativo a los juguetes importados, por ejemplo, el núcleo duro -junto a los productos de decoración de navidad- de las ventas de temporada y el cual supone un negocio de u $\$$ s 400 millones anuales, implicó un volumen de importación en 2014 de u\$d 130 millones de dólares, de los cuales el $60 \%$ fueron realizados por las grandes cadenas de retail y Mc Donalds. Un hecho que enfrentaría al gobierno con la Asociación Argentina de Empresas de Juguetes y Afines, sobre todo las empresas Mattel, Cebra y El Mundo del Juguete. Una relación de fuerzas que se invirtió en un año, dado que en 2012 el mayor peso en la importación lo tenían las empresas de comercialización exclusiva. Incluso, la cámara del sector intentó coordinar acciones con el empresariado del retail, pero las mismas fueron en vano: "Hablamos con los supermercados para coordinar algo en conjunto, pero ellos tienen su propia metodología comercial", comentó el director ejecutivo de la cámara que nuclea a las firmas de juguetes en 2015 (Bidegaray, 2015).

Un quinto factor en la co-determinación del contexto estratégico, radica en el hecho que Precios Cuidados surge tras el ensayo, desde el 2005, de sucesivos controles progresivos, desde el acuerdo de precios con empresas alimenticias, hasta el congelamiento total por 60 días en febrero de 2013. Una medida inédita, en ese entonces, en más de 20 años. De hecho, esta resolución de congelamiento total, antecedió en 11 meses a Precios Cuidados e implicó para los principales proveedores la puesta en suspenso del sistema de precios de más de 50.000 referencias (en el caso de los hipermercados). En este marco, proyectado sobre un horizonte inmediato de tiempo, con el antecedente de un congelamiento total, un programa de administración de 196 productos, resultaría (ante la imposibilidad misma de levantar los controles), un mal menor. Sobre todo, para evitar llegar al período de mayor ventas con un congelamiento total de los productos.

Por último, a los ojos del empresariado del canal moderno de venta minorista, el crecimiento del canal tradicional, sobre todo de la mano de pequeños establecimientos administrados por empresarios de origen chino, disputó de forma creciente la participación en el total de ventas. Sobre todo, porque - en conjunto- a diciembre de 2013 administraban más de 10.000 puntos de venta, como parte de un crecimiento sostenido desde 2003 en el marco de un cambio de hábitos de consumo a partir de la sustitución de compras mensuales, por pequeñas, semanales. Sin embargo, a partir de la puesta en marcha del programa, se modificaría de forma sustancial el peso relativo de cada uno de los canales, de forma tal que -en un contexto de retracción del consumoel canal moderno sólo caería en un 0,8\%, mientras que los almacenes y autoservicios lo harían en casi dos puntos porcentuales, motorizado por el crecimiento de la demanda de los productos del programa.

En suma, el empresariado (moderno) de comercialización minorista argentino llega a las negociaciones sobre Precios Cuidados con su posición como tal condicionada por el desarrollo de seis juegos en paralelo: (a) el crecimiento de la preocupación por parte de la opinión pública del fenómeno de la inflación; (b) la necesidad del gobierno de tomar posición; (c) la limitación del margen de acción del empresariado y el ejercicio del poder instrumental (fruto de los factores "a" y "b"); (d) un horizonte temporal caracterizado por (d1) un antecedente inmediato de congelamiento total, y (d2) un mediano plazo signado por la inminencia de la temporada de mayor venta y el Mundial de Futbol como evento central (dos hitos comerciales dependientes de la 
autorización de cuotas de importación de juguetes y productos tecnológicos); (e) la reforma en el diseño institucional de la Secretaría de Comercio, a partir de la unificación de Comercio Interior y Exterior; y (f) el crecimiento en los último 10 años en la participación de ventas de los canales tradicionales, en detrimento de las grandes cadenas.

En este contexto, desde la óptica del empresariado, el programa de Precios Cuidados constituiría una ventana de oportunidad para la gestión de intereses sectoriales en el marco de negociaciones más fluidas con el gobierno (fruto de las instancias trimestrales de revisión de precios y el reporte semanal de alertas tempranas de desabastecimiento). En lo inmediato, supondría un esfuerzo por reducir y contener el congelamiento de precios total de la economía, a la administración de una canasta de 196 productos. El equivalente al 0,4\% del total de productos vendidos en un hipermercado, en lugar del $100 \%$. En el mediano plazo, en cambio, posibilitaría, a través de esas mismas instancias de diálogo, negociar cuotas de importación de productos de cara a eventos comerciales de trascendencia sectorial. A punto tal de ganar participación sobre el total de volumen importando de ítems claves, como los juguetes, frente a las cadenas especializadas en ese rubro.

De esta forma, se configurará un escenario en donde el empresariado tendrá acceso de forma regular a negociaciones con las mismas autoridades que debían no sólo controlar el programa, sino también aprobar los planes de importación, en un contexto marcado por la inminencia de eventos comerciales importantes para el sector; dando forma a un escenario emergente más favorable a sus intereses.

En una palabra, el apoyo al programa, aun cuando implicaba un aumento de los controles y las capacidades del Estado, también suponía tres conquistas para el empresariado moderno del retail. En primer lugar, una mejora en su poder instrumental a partir de la institucionalización de mesas de negociación con autoridades de gobierno. Sobre todo, en términos relativos con otros sectores, como las cadenas comercializadoras de juguetes o las cadenas regionales, de autoservicios minoristas, por mencionar algunas. En este sentido, si bien su poder no podrá eliminar la cuestión de los controles de la agenda, sí podrá - a partir de la consagración de las instancias de negociación previstas por el programa- negociar el alcance del mismo, los márgenes, los costos de transacción y logística, el flujo de mercadería importada, entre otras cuestiones.

En segundo término, el diseño del programa revitalizará el poder de las cámaras sectoriales. So- bre todo, porque su economía de funcionamiento supondrá canalizar a través de ellas las negociaciones trimestrales sobre márgenes, precios, faltantes, entre otros. Reduciendo los costos de transacción y brindando un marco para el ejercicio del poder instrumental del empresariado.

En tercero, obtendrán una creciente participación de mercado en la medida en que el programa evidenciara niveles de aceptación importantes. Sobre todo, en contraposición a los supermercados de origen chino. De hecho, conforme datos de la consultora CCR, las grandes cadenas registraron en octubre de 2014 un crecimiento en sus ventas en unidades del orden del 1,2\%, contra una caída del 3,2 del canal tradicional, fundamentalmente supermercados chinos, almacenes y negocios de barrio. Incluso, comparando el primer semestre de 2014 (enero a junio), se observa que las ventas en los autoservicios registraron una caída del 8,1\% en unidades, contra el 0,7\% de los supermercados (Sainz, 2014). Además, según los datos oficiales de la propia CASRECH, en el 2014 cerraron más de 500 supermercados chinos. A fines de 2013, la cámara contabilizaba 10.788 locales nucleados a su interior, un $4 \%$ más que los reportados en marzo de 2015 (10.316) (Glickman, 2015).

En una palabra, Precios Cuidados, en tanto que política de protección del mercado local de precios, devendría en un dispositivo clave en la gestión de los intereses de la agenda de liberalización del flujo de circulación de bienes internacionales.

A cambio de estas "conquistas" relativas, el empresariado no sólo participará voluntariamente del programa, contribuyendo al desarrollo y extensión de las capacidades estatales (Quiroga, 2015), sino que también otorgará a las agencias de gobierno implicadas un capital de suma importancia: su experiencia. Después de todo, la experiencia deviene en un activo clave con vistas al éxito de la acción de gobierno, en por lo menos tres sentidos (Schneider, 2004): permite buscar información en materia de actividad económica, por fuera de la burocracia tradicional; disponer de medios más efectivos de comunicación sobre cambios en materia de políticas; y delegar aspectos de la política, como la implementación en el piso de venta y la financiación (dado que no se aportan subsidios para el sostenimiento de precios, sino que son las empresas las que reducen sus márgenes como condición para mantener los mismos). 


\section{Conclusiones}

La investigación precedente nos pone frente a tres series de cuestiones de suma importancia en lo que hace al debate sobre la tensión, al interior de los mercados nacionales, entre la liberalización y las prácticas proteccionistas.

En primer lugar, pone de manifiesto la densidad propia de los vínculos entre las agencias estatales y el empresariado. En lo que respecta al caso analizado, aun cuando una facción del empresariado no pudo definir el diseño de un política pública de control de precios, ni eliminar opciones de la discusión; sí pudo mejorar su poder relativo al interior del retail local a partir de influenciar -en el mediano plazolos resultados emergentes de una política inevitable, sobre la base de un activo clave: su experiencia de operación en el mercado y la financiación indirecta del programa a partir de la reducción de los márgenes de rentabilidad, la intervención en el piso de venta, la asignación de recursos para su implementación, entre otros. Dos garantías no sólo de su buen funcionamiento, sino también de una alta visibilidad para el programa y bajos costos para el Estado y sus agencias.

En segundo lugar, nos pone frente a tres desafíos metodológicos de suma importancia. En primer término, reconocer que la necesidad de poner al Estado en relación con su otredad: con las estructuras de mercado. Sobre todo, a los efectos de evitar cualquier definición ex ante, pasiva o subordinada del papel del empresariado, su organización y accionar, en el proceso bajo análisis.

En segundo término, y una vez asumido lo anterior, se hace necesario reconstruir las múltiples arenas en las que el accionar empresarial se despliega, en tanto que actor social. Sólo de esta forma se logra dar cuenta de los intereses en juego, así como dimensionar la significación misma de las cuestiones en debate y del accionar en sí.

A su vez, el caso bajo análisis pone de manifiesto el carácter limitado de ciertas conceptualizaciones binarias, la cuales -aun con ciertos beneficios en términos de economía argumental- nos mantienen ciegos a los pliegues en los cuales relaciones más densas entre políticas de protección (del mercado de precios, en nuestro caso) y agendas de liberalización de la circulación de bienes importados, no sólo coexisten sino que dependen una de la otra.

La razón binaria entre la protección local y la liberalización global teje - en una palabra- una suerte de creencias y limitaciones conceptuales que -en consonancia con el dicho popular- atrapa moscas (ilumina ciertas relaciones) a riesgo -fruto de su sobresimplificación- de dejar escapar elefantes.

Por último, la discusión sobre el valor de los bienes de consumo se inserta al interior de un denso entramado de relaciones y abordajes, que exceden al hecho económico y nos pone frente a la discusión de los límites de la capacidad absoluta del Estado, así como de sus agencias para intervenir el tejido social de forma coordinada y consistente. Cada vez más, su realización, la de sus políticas y fines, dependen de la articulación de sus burocracias con actores no-estatales, incluso, a partir de prácticas informales. En una palabra, en el barro de la historia de las capacidades del Estado, es sus pliegues, en sus falencias, en su funcionamiento híbrido, no encontramos un desvío o una anomalía, sino más bien, la verdad de su funcionamiento. O más aún: la condición de su eficacia.

\section{Referencias}

Alderman, H. (2002). Subsidies as a social safety net: effectiveness and challenges. Social Safety Net Primer Series, Discussion Paper, 224.

Bertranou, J. (2013). Capacidad estatal: aportes al debate conceptual. En Séptimo Congreso Argentino de Administración Pública.

Bidegaray, M. (2015). Importación de juguetes: Los súper pueden traer más que otros comercios.

Bienen, H. S. y Gersovitz, M. (1986). Consumer subsidy cuts, violence, and political stability. Comparative Politics, 19(1):25-44.

Broockman, D. E. (2012). The problem of preferences: Medicare and business support for the welfare state. Studies in American Political Development, 26(02):83-106.

Colander, D. (1984). Galbraith and the theory of price control. Journal of Post Keynesian Economics, 7(1):30-42.

Dahl, R. A. (1982). Dilemmas of pluralist democracy: Autonomy vs. control, volumen 31. Yale University Press.

Dunn, S. P. y Pressman, S. (2005). The Economic Contributions of John Kenneth Galbraith. Review of Political Economy, 17(2):161-209.

Evans, P. y Rueschemeyer, D. (1985). The Sate and Economic Transformation: Toward an Analysis of the Conditions Underlying Effective Intervention. En Evans, P., Rueschemeyer, D., y Skocpol, T., editores, Bringing the State Back In, pp. 334. Cambridge University Press., New York. 
FIEL (1990). Control de precios e inflación. La experiencia argentina reciente. Ediciones Mantieal, Buenos Aires.

Ford, A. (1996). De la aldea global al conventillo global. Navegaciones: Comunicación, cultura y crisis. Buenos Aires: Amorrortu Editores, pp. 42-64.

Friedman, M. y Friedman, R. (1990). Free to choose: A personal statement. Houghton Mifflin Harcourt.

Galbraith, J. (1941). The Selection and Timing of Price Controls. The Review of Economic Statistics, 23(2):82-85.

Galbraith, J. (1946). Reflections on Price Control. The Quarterly Journal of Economics, pp. 475489.

Galbraith, J. (1951). The Strategy of Direct Control in Economic Mobilization. The Review of Economic Statistics, 33(1):12-17.

Galbraith, J. (2001). The Essential Galbraith. Houghton Mifflin, Boston.

Glickman, A. (2015). Se frena desembarco chino: cerraron 500 supermercados.

Grayson, C. J. y Neeb, L. (1974). Confessions of a price controller. Ill., Dow Jones-Irwin.

Gutner, T. (2002). The political economy of food subsidy reform: the case of Egypt. Food Policy, $27(5): 455-476$.

Hacker, J. S. y Pierson, P. (2002). Business power and social policy: employers and the formation of the American welfare state. Politics 8 Society, 30(2):277-325.

Kantor, D. (2014). Del almacén a los mini súper: las cadenas pasan a la ofensiva.

Kingdon, J. W. y Thurber, J. A. (1984). Agendas, alternatives, and public policies, volumen 45. Little, Brown Boston.

Lendoiro, F. (2012). Los supermercados lideran ranking de los empleadores.

Lindblom, C. E. (1979). Politics and markets: The world's political-economic systems. Business Horizons, 22(5):80-81.

Mora y Araujo, M. (2011). La Argentina bipolar. Las variantes de la opinión pública. Sudamericana, Buenos Aires.

Nielsen (2015). El $80 \%$ de los argentinos modificó sus hábitos de compra para ahorrar.
O'donnell, G. (1977). Estado y alianzas en la Argentina, 1956-1976. Desarrollo económico, 16(64):523-554.

Pierson, P. (1993). When effect becomes cause: Policy feedback and political change. World politics, 45(04):595-628.

Quiroga, J. P. (2015). Control(es) de Precio y capacidades estatales. Disciplinamiento, transferencia y redes informales de control, monitoreo $y$ sanción. El caso de Precios Cuidados en Argentina y su aceptación por parte del empresariado del retail local. Tesis doctoral, Georgetown University.

Rebon, N. (2014). Aseguran que el consumo deberá mejorar la eficiencia y maximizar las ventas.

Rockoff, H. (2004). Drastic measures: A history of wage and price controls in the United States. Cambridge University Press.

Saylor, R. (2012). Sources of state capacity in Latin America: commodity booms and state building motives in Chile. Theory and society, 41(3):301324 .

Schneider, B. R. (2004). Business politics and the state in twentieth-century Latin America. Cambridge University Press.

Schneider, B. R. (2008). Economic liberalization and corporate governance: the resilience of business groups in Latin America. Comparative politics, 40(4):379-397.

Schneider, B. R. (2009). Hierarchical market economies and varieties of capitalism in Latin America. Journal of Latin American Studies, 41(03):553575 .

Schuettinger, R. L. y Butler, E. F. (1979). Forty centuries of wage and price controls: how not to fight inflation. Ludwig von Mises Institute.

Swinnen, J. y Squicciarini, P. (2012). Mixed Messages on Prices and Food Safety. Science Magazine.

Taussig, F. W. (1919). Price-Fixing as seen by a Price-Fixer. The Quarterly Journal of Economics, 33(2):205-241.

Tsebelis, G. (1990). Nested games: Rational choice in comparative politics, volumen 18. Univ of California Press.

Verón, E. (1995). Psicología y sociología. En Conducta, estructura y comunicación. Escritors teóricos 1959-1973. Amorrortu, Buenos Aires. 